ORIGINAL ARTICLE

\title{
Effect of intense wrestling exercise on leucocytes and adhesion molecules in adolescent boys
}

\author{
D Nemet, P J Mills, D M Cooper
}

Br J Sports Med 2004;38:154-158. doi: 10.1136/bjsm.2002.002576

See end of article for authors' affiliations

....................

Correspondence to:

Professor Cooper,

University of California,

Irvine, UCl Clinical

Research Center, Building

25, 2nd floor, 101 The

City Drive, Orange, CA

92868, USA; dcooper@

uci.edu

Accepted 17 March 2003
Background: In adults, exercise is a powerful and natural stimulator of immune cells and adhesion molecules. Far less is known about exercise responses during childhood and adolescence and whether or not exercise in "real life" activities of healthy adolescents influences immune responses.

Objective: To determine if strenuous exercise leads to significant changes in leucocyte number and adhesion molecule expression in adolescent boys.

Methods: Eleven healthy, high school boys, aged 14-18.5 years, performed a single, typical, 1.5 hour wrestling practice session. Blood was sampled before and after the session. Flow cytometry was used to evaluate changes in immune responses.

Results: The exercise led to significant $(p<0.05)$ and robust increases in granulocytes, monocytes, and all lymphocyte subpopulations. The most significant changes were observed for natural killer cells $(p<0.0005)$. The number of T cytotoxic and T helper cells expressing CD62L increased significantly $(p<0.002$ and $p<0.0005$ respectively), as did the number of T cytotoxic and T helper cells not expressing CD62L $(p<0.003$ and $p<0.009$ respectively). The density of CD62L on lymphocytes decreased significantly with exercise $(p<0.0005)$, whereas CD1 la $(p<0.01)$ and CD54 ( $<<0.01)$ increased.

Conclusions: The data show that an intense wrestling bout in adolescent boys leads to profound stimulation of the immune system. The role of these common changes in overall immune status and the development of the immune and haemopoietic systems has yet to be determined.
${ }^{t}$ is increasingly recognised that brief episodes of physical exercise can substantially influence the type and numbers of circulating white blood cells. ${ }^{2}{ }^{2}$ Naturally, most investigators have focused on the importance of this effect with regard to immune function and the organism's ability to respond to infection. During childhood and adolescence, adaptive consequences of white blood cell responses to exercise may prove to be important for overall development of the haemopoietic and immune systems as well as for the fundamental process of growth.

Although it is known that exercise leads to leucocytosis in adults, few studies of exercise immune effects have been carried out in children. ${ }^{3-6}$ Moreover, it is now possible to examine the effect of exercise on leucocytes with much greater specificity as to immunological subgroups of cell types. This is potentially useful information, particularly in children, because different leucocyte populations have different physiological functions and produce distinct hormones and growth mediators that could alter the well recognised growth responses of physical activity. ${ }^{7}$ The purpose of this study was to determine the effect of intense exercise on the subpopulations of leucocytes in the circulation and on the expression of key adhesion molecules that play a role in leucocyte trafficking-that is, L-selectin (CD62L), intercellular adhesion molecule-1 (ICAM-1, CD54), and leucocyte function associated antigen I (LFA-1, CDIla). A study of this nature has not previously been performed in adolescent boys, particularly under field conditions such as associated with high school sports like wrestling.

We hypothesised that a strenuous field exercise would lead to substantial alterations in leucocytes and mediators of their trafficking-for example, appreciable leucocytosis (as has been previously shown in adults and children) and increases in ICAM-1. To test this, we studied the effect of a single, typical, high school wrestling practice session in a group of adolescent boys. Wrestling was chosen because individual practice sessions are quite intense, and because it involves forms of exercise (resistive, eccentric) known to cause local inflammation if not frank microfibre injury. We recently reported the effects of wrestling practice on inflammatory cytokines and growth mediators, showing a robust increase in catabolic inflammatory mediators-for example, interleukin 6-and a simultaneous decrease in anabolic growth factors such as insulin-like growth factor-I. ${ }^{8}$

\section{METHODS}

\section{Sample population}

The study was approved by the institutional review board, University of California, Irvine (UCI) and written informed consent as well as assent were obtained. Eleven healthy adolescent boys participated (table 1). The study was designed to examine responses of peripheral blood mononuclear cells and adhesion molecules to intense exercise in a field setting in which each participant served as his own control. There was no independent, non-exercising control group. No subjects were receiving any drugs at the time of the study.

\section{Measurement of height, weight, and body mass index (BMI) \\ Standard calibrated scales and stadiometers were used to determine height, weight, and BMI (weight $(\mathrm{kg}) /$ height $(\mathrm{m})^{2}$ ). As BMI changes with age, we calculated the BMI centile for each child using the recently published standards from the Centers for Disease Control, National Center for Health Statistics. ${ }^{9}$ Weight was measured before and at the end of the practice.}

Abbreviations: BMI, body mass index; ICAM-1, intercellular adhesion molecule-1 (CD54); LFA-1, leucocyte function associated antigen-1 (CDI la) 


\begin{tabular}{ll} 
Table 1 & Subject characteristics $(\mathrm{n}=11)$ \\
\hline Age $($ years $)$ & $16.5(0.5)(14-18.5)$ \\
Weight $(\mathrm{kg})$ & $75.4(2.9)(59.5-92.3)$ \\
Height $(\mathrm{cm})$ & $171.8(1.8)(161-178)$ \\
$\mathrm{BMI}\left(\mathrm{kg} / \mathrm{m}^{2}\right)$ & $25.5(0.8)(22.2-30.8)$ \\
$\mathrm{BMl}$ centile & $83.6(4)(49-98)$ \\
Peak $\mathrm{VO}_{2}(\mathrm{ml} / \mathrm{min} / \mathrm{kg})$ & $44.5(2)(37-54)$ \\
\hline \multicolumn{2}{l}{ Values are mean (SEM) (range). } \\
BMl, Body mass index.
\end{tabular}

\section{Measurement of cardiorespiratory fitness}

On a separate day, within one week of the wrestling practice, each volunteer underwent standard measurements of cardiorespiratory fitness. Each subject performed a ramp-type progressive exercise test on a cycle ergometer in which he exercised to the limit of his tolerance. Vigorous encouragement was given during the high intensity phases of the exercise protocol. Gas exchange was measured breath by breath, ${ }^{10}$ and the $\mathrm{VO}_{2}$ peak was determined as previously described for children and adolescents. ${ }^{11}$

\section{Field study}

The wrestling practice was held about six weeks after the end of the wrestling season. The field study was designed to mimic real life exercise, such as is encountered in the daily activities of these adolescents. To accomplish this, we arranged a 1.5 hour wrestling practice modelled on typical sessions of this sport. The practice was coached by one of the wrestling team coaches. None of the subjects trained during the day preceding the blood sampling. The subjects were instructed to have a light breakfast on the morning of the test, and the exercise session began at about noon. Subjects were admitted to the General Clinical Research Center (GCRC) at the University of California, Irvine. The study took place at the wrestling facility of the UCI faculty/student recreation centre.

Wrestling practice involves both aerobic and anaerobic exercise and both concentric and eccentric types of movement. The practice consisted of:

- Warm up (20 minutes): jogging, "stretch" exercise with sports specific calisthenics such as push ups and sit ups.

- Technique drills (20 minutes): the subjects performed typical wrestling skills including take downs, escapes, pin combinations, and pin counters. The technique drills involved high intensity exercise of short duration (6-10 seconds).

- Situation wrestling (15 minutes): the subjects were paired or placed in groups of three. Specific wrestling positions were assigned, and subjects wrestled from the given situation practicing a specific move and its counters. This involved exercise at maximal effort in bursts of 1520 seconds.

- "Iron man" (15 minutes): wrestlers were placed in groups of five or six with one wrestler in each group designated the "iron man". The "iron man" continuously wrestled facing a new partner every 30 seconds. Designation of "iron man" rotated after about three or four minutes. Each wrestler was the "iron man" at least once during this drill.

- Live wrestling (10 minutes): each wrestler was paired with a partner of similar weight and ability. Each pair wrestled a full six minute match.

As frequent blood sampling would have been unfeasible in the context of a vigorous wrestling exercise, we sampled blood twice, before and immediately after the exercise training session, by standard phlebotomy. The mean (SD) time interval between the end of the training session and phlebotomy was 41 (4) seconds (27-70). Samples were maintained at room temperature $\left(23^{\circ} \mathrm{C}\right)$ and transported to the flow cytometry laboratory. Heart rate was measured by individual palpation at baseline and at three time points (20, 50 , and 80 minutes) during the practice. As is typically the case in high school wrestling practices, subjects were permitted free access to water and encouraged to drink when thirsty and rest briefly when excessively fatigued.

\section{Serum measurements \\ Lactate}

Lactate was measured with the use of a YSI lactate analyser (YSI 1500; Yellow Springs, Ohio, USA). The intra-assay coefficient of variation was $2.8 \%$, the interassay coefficient of variation was $3.5 \%$, and the sensitivity was $2 \mathrm{~g} / \mathrm{l}$.

\section{Flow cytometry}

Whole blood was preserved with EDTA and maintained at room temperature $\left(23^{\circ} \mathrm{C}\right)$. As previously described, ${ }^{12}$ flow cytometry (FACSCalibur; Becton Dickinson, San Jose, California, USA) using CellQuest software was used to quantify leucocytes and lymphocyte subsets and CD62L and CD54 expression. A complete blood count analysis was performed using a Coulter STKS CBC counter. Whole blood was stained with monoclonal antibodies conjugated to various fluorochromes (Becton-Dickinson and PharMingen). The lysing reagent was FACS Brand Lysing Solution (Becton-Dickinson) which results in simultaneous lysis of red blood cells and partial fixation of leucocytes. Fluorescence compensation was performed using CaliBRITE beads (Becton-Dickinson) and FACSComp software. Optimal amounts of antibodies were used, and 8000-15 000 events were analysed per tube. Isotypic controls were used for each assay to determine non-specific staining. In addition to determining CD62L and CD54 expression, we determined CD62L, CD54, and CD1la density on mixed lymphocytes. For density determinations, flow cytometric estimation of antibodies bound/cell was performed using Quantibrite PE beads (Becton-Dickinson). The number of antibodies bound to the specific cell or microbead population provides a good approximation of antigen density expressed on the cell. The Quantibrite PE beads were run at the same instrument settings as the assay, and the FL2 (PE) axis was converted into the number of PE molecules bound/cell.

\section{Statistical analysis}

Paired $t$ tests were used to determine changes after exercise. $\alpha$ was set at 0.05 . Correlation and linear regression analyses were computed between changes in lactate, leucocytes, and adhesion molecules as well as with BMI and indexes of fitness. Data are presented as mean (SEM). Figure 1 shows the mean (SEM) of the percentage changes found in each subject. This is not identical with the percentage change that would be calculated using the mean values of the whole group before and after exercise.

\section{RESULTS}

Height, weight, BMI, and fitness level

Table 1 shows the subject characteristics. Weight had decreased significantly after the practice $(75.4(2.9)$ to 74.7 (2.9) $\mathrm{kg}, \mathrm{p}<0.018$ ).

\section{Cardiorespiratory effects of the wrestling practice}

All 11 subjects completed the $1.5 \mathrm{~h}$ practice. Mean baseline heart rate was 74 (2) beats/min. Mean heart rate at three measurement points during the practice $(20,50$, and 80 minutes) was 163 (3), 160 (4), and 163 (3) beats/min 


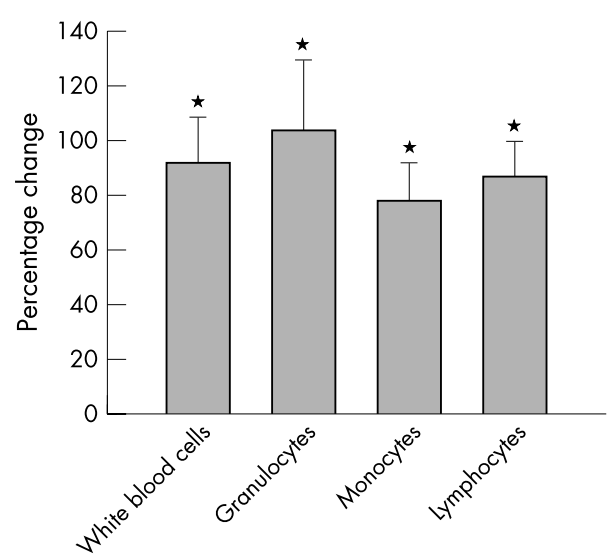

Figure 1 Effect of a wrestling practice on white blood cells and subpopulations. A significant increase was observed in all leucocyte subpopulations. ${ }^{*} \mathrm{p}<0.05$.

respectively. Lactate concentration increased by 441 (67)\% $(\mathrm{p}<0.005)$.

\section{Response to the wrestling exercise}

As shown in tables 2 and 3 and figs 1 and 2, the wrestling exercise led to a significant increase in the number of all circulating white blood cells, including granulocytes, monocytes, mixed lymphocytes, CD19 B cells, CD3 T cells, CD3CD8 $\mathrm{T}$ cytotoxic cells, CD3CD4 T helper cells, and CD $3{ }^{-} \mathrm{CD} 16 \mathrm{CD} 56$ natural killer cells.

The CD4:CD8 ratio had decreased after exercise (table 2).

The number of CD3CD8 T cytotoxic cells expressing CD62L (CD8CD62L) increased significantly, as did the number of CD4CD62L T helper cells and the number of T helper cells not expressing CD62L (CD4CD62L ${ }^{-}$). Both CD54 and CD54 mixed lymphocytes increased in the circulation. The density of CD54 on mixed lymphocyte increased, as did the density of CDIla (table 3).

Packed cell volume had increased by the end of exercise from 0.47 to $0.49(\mathrm{p}<0.005)$. However, the overall change was equivalent to only a $4.4 \%$ change in concentration. Thus, the change in packed cell volume was substantially smaller than the large changes in peripheral blood mononuclear cells and adhesion molecules.

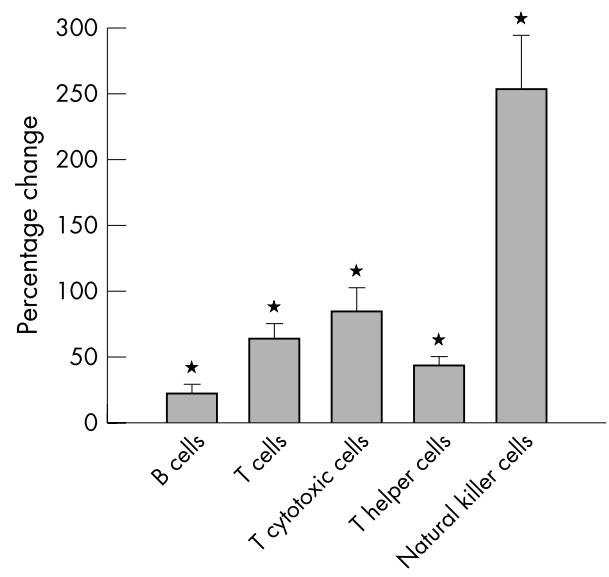

Figure 2 Effect of a wrestling practice on subgroups of lymphocytes. A significant increase was observed in all lymphocyte subpopulations, predominantly natural killer cells and T cells. ${ }^{*} \mathrm{p}<0.05$.
Table 2 Circulating leucocytes and lymphocyte subsets before and after exercise

\begin{tabular}{llll}
\hline & Before & After & p Value \\
\hline White blood cells & $6993(423)$ & $13436(1339)$ & 0.0005 \\
Granulocytes & $3848(296)$ & $7719(885)$ & 0.001 \\
Lymphocytes & $2548(179)$ & $4651(408)$ & 0.0005 \\
Monocytes & $597(50)$ & $1069(128)$ & 0.0005 \\
CD3 ${ }^{-}$CD 16CD56 NK cells & $434(47)$ & $1466(207)$ & 0.0005 \\
CD19 B cells & $458(54)$ & $540(46)$ & 0.029 \\
CD3 T cells & $1616(127)$ & $2571(221)$ & 0.0005 \\
CD3CD4 T-helper cells & $859(69)$ & $1215(91)$ & 0.0005 \\
CD3CD8 T cytotoxic cells & $671(58)$ & $1214(158)$ & 0.002 \\
CD4:CD8 ratio & $1.31(0.07)$ & $1.06(0.07)$ & 0.002 \\
\hline Values are cells/ $\mu$ and are expressed as mean (SEM). & \\
NK, Natural killer. & & &
\end{tabular}

Correlation between fitness, BMI, and increase in lactate concentrations with leucocyte responses to the wrestling practice

We found no correlation between fitness (peak $\mathrm{Vo}_{2} / \mathrm{kg}$ ) or BMI and the magnitude of change in response of any of the leucocytes or adhesion molecules to exercise. Exercise associated increases in lactate, however, correlated significantly with the increases in leucocytes $(r=0.644, \mathrm{p}<0.009$, fig 3), granulocytes $(r=0.675, \mathrm{p}<0.023)$, and CD54 lymphocytes ( $\Delta$ CD54 lymphocytes, $r=0.79, \mathrm{p}<0.004$ ).

\section{DISCUSSION}

This is the first study to show acute, substantial responses of leucocytes and adhesion molecules to field exercise in a population of healthy adolescent boys. Although representing an intense level of physical activity, the wrestling practice protocol is encountered in the lives of many adolescents and is not atypical of the intensity found in other high school level individual and/or team sports. The data also show that exercise intensity (represented by the change in lactate concentration) can influence the immune response to brief periods of intense exercise in adolescent boys.

It has been shown that sustained exercise leads to an abrupt (first 10-20 minutes) increase in leucocytes in adults. ${ }^{13}$ This initial increase in the number of circulating leucocytes is believed to result from recruitment of cells from the marginal pool. ${ }^{14}$ The pulmonary and splanchnic vasculature are considered to be important reservoirs of this marginated pool. ${ }^{15}{ }^{16}$ Consistent with this, we found significant increases in the number of circulating white blood cells, including granulocytes, monocytes, mixed lymphocytes,

Table 3 Expression of lymphocyte adhesion molecules before and after exercise

\begin{tabular}{llll}
\hline & Before & After & p Value \\
\hline CD8CD62L & $416(38)$ & $557(42)$ & 0.002 \\
CD8CD62L & $255(20)$ & $657(116)$ & 0.003 \\
CD62L density on CD8* & $10103(633)$ & $7677(621)$ & 0.0005 \\
CD62L density on & $10806(453)$ & $8089(432)$ & 0.0005 \\
lymphocytes* & & & \\
CD4CD62L & $748(63)$ & $1030(76)$ & 0.0005 \\
CD4CD62- & $111(4)$ & $185(15)$ & 0.009 \\
CD62L density on CD4* & $11309(464)$ & $9053(426)$ & 0.0005 \\
CD54 lymphocytes & $899(128)$ & $1428(224)$ & 0.0005 \\
CD54- lymphocytes & $1649(51)$ & $3223(184)$ & 0.0005 \\
CD54 density on & $980(46)$ & $1154(59)$ & 0.007 \\
lymphocytes* & & & \\
CD1 la density on & $19130(1075)$ & $23993(1328)$ & 0.0005 \\
lymphocytes* & & & \\
\hline
\end{tabular}

Values are cells $/ \mu$ and are expressed as mean (SEM) ${ }^{*}$ Antibodies bound/cell. 


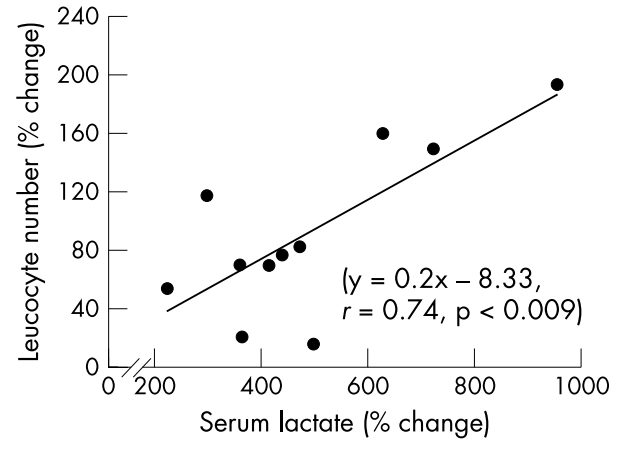

Figure 3 Correlation between changes in lactate concentrations and changes in leucocyte number. The change in the number of leucocytes correlated positively with the degree of the metabolic stress imposed by the exercise (expressed as change in lactate concentration).

$\mathrm{T}$ cells, and natural killer cells (table 2, fig 1) after the wrestling exercise.

In response to exercise in both adults and children, ${ }^{17}{ }^{18}$ stress hormones, including adrenaline (epinephrine) and noradrenaline (norepinephrine), increase (not measured in this study). The influence of exercise induced changes in catecholamines on lymphocyte trafficking is determined, in part, by the density of $\beta_{2}$ adrenergic receptor on the lymphocytes. ${ }^{19}$ After the wrestling practice, we found increases in all lymphocyte subsets, but the magnitude of change within the subsets differed. Natural killer cells have the highest density of $\beta_{2}$ receptors on their surface and are known to be the cell type most respondent to exercise or catecholamine injection. ${ }^{20}$ Consistent with this, we found the change in natural killer cell number to be the most prominent change (fig 2). Natural killer cells play a pivotal role in the first line of the host defence system to foreign pathogens, but also increase in response to other stress-for example, psychosocial. $^{21}$

In adults, the initial increase in natural killer cell number after exercise usually persists for a brief time (hours), and is followed by a decrease (exercise associated leucopenia ${ }^{22}$ ). Whether this biphasic pattern exists in children and adolescents after exercise and the precise biological role has not been determined.

After natural killer cells, $\beta_{2}$ receptor density decreases progressively on $\mathrm{T}$ cytotoxic cells, $\mathrm{T}$ helper cells, and $\mathrm{B}$ cells. ${ }^{23}{ }^{24} \mathrm{~T}$ cytotoxic cells and $\mathrm{T}$ helper cells increased with exercise in our study while B cells showed a small significant change, and the pattern of these changes in lymphocyte subpopulations paralleled the pattern of $\beta 2$ receptor density (fig 2).

Both CD4 (T helper) and CD8 (T cytotoxic) lymphocytes increased but the increase in CD8 was greater. Consequently, there was a significant decrease in the CD4:CD8 ratio, which has been used to gauge the degree of immunodeficiency in pathological states. ${ }^{25}$ Similarly to these findings in adolescents, strenuous exercise is known to elicit an initial decrease in the CD4:CD8 ratio in adults. ${ }^{26}{ }^{27}$ Shek et al ${ }^{27}$ suggested that this decrease may contribute to the exercise induced immune compromise, particularly in the recovery period. In contrast, fitter elderly subjects tend to have higher CD4:CD8 ratios. ${ }^{28}$ The physiological importance of exercise alterations in the CD4:CD8 ratio of adolescents and/or its influence on the development of the immune system is not yet known.

This study shows that in children, as in adults, strenuous exercise influences adhesion molecules. ${ }^{29-31}$ CD62L (L-selectin) mediates leucocyte rolling and adhesion to endothelium at the site of inflammation. We found an increase in both $\mathrm{CD}^{-} \mathrm{L}^{-}$and CD62L with a preferential significant increase in $\mathrm{CD} \mathrm{L}^{-} \mathrm{T}$ cell subsets (table 3 ). The relative increase in circulating $\mathrm{CD} 2 \mathrm{~L}^{-}$lymphocytes is believed to result from preferential release into the circulation of $\mathrm{CD} 2 \mathrm{~L}^{-}$cells from the marginal pool (primarily the spleen) rather than actual downregulation of L-selectin in response to exercise. ${ }^{12} 3233$ The decreased density of CD62L on circulating lymphocytes, mainly CD8 and CD4 cells, is consistent with previous exercise studies. ${ }^{34}$ As L-selectin is typically shed and CDIla is upregulated on T lymphocytes as the cell changes from a naïve to a post-antigen presented memory $\mathrm{T}$ cell, ${ }^{35}$ these findings suggest that the wrestling exercise led to recruitment of memory $\mathrm{T}$ cells into the peripheral circulation from the marginal pool-that is, the marginal pool serves as a reservoir to memory cells. ${ }^{36}$ It is well documented that, compared with naïve cells, memory cells have increased interaction capacity with activated endothelium as well as the ability to selectively recruit into inflammatory sites. ${ }^{37} 38$ Finally, these memory T cells (marked also as CD45RO) are also known to be associated with increased production of inflammatory cytokines such as interleukin $6 .^{39}{ }^{40}$ We have recently shown ${ }^{8}$ that wrestling led to large increases in circulating concentrations of interleukin 6, suggesting that $\mathrm{T}$ memory cells may play a role in the inflammatory response after exercise.

Lymphocytes expressing CD54 increased in response to wrestling, a response similar to that observed previously after heavy exercise in adults. ${ }^{29} \mathrm{CD} 54$ is constitutively expressed on the surface of some lymphocytes, and is upregulated in response to a variety of inflammatory mediators, including proinflammatory cytokines, certain hormones, cellular stress, and viral infection. ${ }^{41}$ Interestingly, CD54 and CD1la are known to be raised in children with asthma exacerbations and are believed to play a major role in the enhanced migration of mononuclear cells and eosinophils observed in allergic asthma. ${ }^{42-44}$ Whether the exercise associated increase in CD54 and CD1la that we observed in healthy children under field conditions plays a role in the common occurrence of exercise induced asthma in childhood has not been examined.

Finally, we have shown that, in adolescents as in adults, the magnitude of the responses of both leucocytes and adhesion molecules correlates with the metabolic stress imposed by the wrestling exercise (represented by lactate produced by the working muscles, fig 3). Boas et al ${ }^{5}$ obtained similar findings on leucocyte number in children performing laboratory exercise. We found no correlation between fitness level or BMI centile and the magnitude of the immune response. This may be because the subjects in this study were all relatively fit, and their high BMI centile may actually be due to increased muscle mass rather than increased fat. We did not carry out an independent assessment of body composition-for example, by dual $x$ ray absorptiometry.

In summary, we here provide the first data showing significant effects of field exercise on immune cell subsets in healthy adolescents. We also show the effect of exercise on adhesion molecules such as LFA-1, L-selectin, and ICAM-1. The rapid and substantial immune response in the field (real life) exercise suggests that stimulation of the immune system often occurs in the lives of children and adolescents and may play a role in its development. There are mounting data to support the idea that there are distinct developmental periods that influence the extent to which exercise and fitness can have long term effects on subsequent growth. ${ }^{45}$ Whether or not exercise associated immune stimulation can alter the functioning of the immune system at different maturational stages remains an enigma. 


\section{Take home message}

During childhood and adolescence, intense bouts of exercise serve as powerful stimuli to the immune system. The overall effect of these stimuli on immunity, however, is yet to be determined.

\section{ACKNOWLEDGEMENTS}

This work was supported by grants MOl-RR00827, HL-57265, and HD-23969 from the National Institutes of Health. DN is a Postdoctoral Research Fellow of the Joseph W Drown Foundation.

\section{Authors' affiliations}

D Nemet, D M Cooper, University of California, Irvine, CA, USA

P J Mills, University of California, San Diego, CA, USA

\section{REFERENCES}

1 Nieman DC, Pedersen BK. Exercise and immune function. Recent developments. Sports Med 1999;27:73-80.

2 Pedersen BK, Hoffman-Goetz L. Exercise and the immune system: regulation, integration, and adaptation. Physiol Rev 2000;80:1055-81.

3 Eliakim A, Wolach B, Kodesh E, et al. Cellular and humoral immune response to exercise among gymnasts and untrained girls. Int I Sports Med 1997; 18:208-12.

4 Wolach B, Eliakim A, Gavrieli R, et al. Aspects of leukocyte function and the complement system following aerobic exercise in young female gymnasts. Scand J Med Sci Sports 1998;8:91-7.

5 Boas SR, Joswiak ML, Nixon PA, et al. Effects of anaerobic exercise on the immune system in eight- to seventeen-year-old trained and untrained boys. J Pediatr 1996:129:846-55.

6 Boas SR, Danduran MJ, McColley SA, et al. Immune modulation following aerobic exercise in children with cystic fibrosis. Int J Sports Med 2000;21:294-301.

7 Wu H, Devi R, Malarkey WB. Localization of growth hormone messenger ribonucleic acid in the human immune system: a Clinical Research Center study. J Clin Endocrinol Metab 1996;81:1278-82.

8 Nemet D, Oh Y, Kim HS, et al. The effect of intense exercise on inflammatory. cyotkines and growth mediators in adolescent boys. Pediatrics 2002;110:681-9.

9 Kuczmarski RJ, Ogden CL, Grummer-Strawn LM, et al. CDC growth charts: United States. 314, 1-28. 6-8-2000. Advance Data. Atlanta: Centers for Disease Control and Prevention/National Center for Health Statistics, 2000.

10 Beaver WL, Lamarra N, Wasserman K. Breath-by-breath measurement of true alveolar gas exchange. J Appl Physiol 1981;51:1662-75.

11 Cooper DM, Weiler-Ravell D, Whipp BJ, et al. Aerobic parameters of exercise as a function of body size during growth in children. J Appl Physiol 1984:56:628-34.

12 Mills PJ, Rehman J, Ziegler MG, et al. Nonselective beta blockade attenuates the recruitment of CD62L(-)T lymphocytes following exercise. Eur J Appl Physiol 1999;79:531-4

13 Gabriel HHW, Kinderman W. Adhesion molecules during immune response to exercise. Can J Physiol Pharmacol 2001;76:512-23.

14 Foster NK, Martyn JB, Rangno RE, et al. Leukocytosis of exercise: role of cardiac output and catecholamines. J Appl Physiol 1986;61:2218-23.

15 Nielsen HB, Secher NH, Kristensen JH, et al. Splenectomy impairs lymphocytosis during maximal exercise. Am J Physiol 1997;272/6 Pt 2):R1847-52.

16 Hogg JC. Neutrophil kinetics and lung injury. Physiol Rev 1987;67:1249-5.

17 Brooks S, Burrin J, Cheetham ME, et al. The responses of the catecholamines and beta-endorphin to brief maximal exercise in man. Eur J Appl Physiol 1988;57:230-4.

18 Rowland TW, Maresh CM, Charkoudian N, et al. Plasma norepinephrine responses to cycle exercise in boys and men. Int J Sports Med 1996;17:22-6.
19 Livnat S, Madden KS, Felten DL, et al. Regulation of the immune system by sympathetic neural mechanisms. Prog Neuropsychopharmacol Biol Psychiatry 1987; 11:145-52.

20 Malm C, Lenkei R, Sjodin B. Effects of eccentric exercise on the immune system in men. J Appl Physiol 1999:86:461-8.

21 Mills PJ, Dimsdale JE. The effects of acute psychologic stress on cellular adhesion molecules. J Psychosom Res 1996;41:49-53.

22 Shephard RJ, Shek PN. Effects of exercise and training on natural killer cell counts and cytolytic activity: a meta-analysis. Sports Med 1999;28:177-95.

23 Maisel AS, Motulsky HJ. Receptor redistribution does not accompany terbutaline-induced down regulation of beta-adrenergic receptors on human mononuclear leukocytes. Clin Pharmacol Ther 1987;42:100-6.

24 Maisel AS, Knowlton KU, Fowler P, et al. Adrenergic control of circulating lymphocyte subpopulations. Effects of congestive heart failure, dynamic exercise, and terbutaline treatment. J Clin Invest 1990;85:462-7.

25 Phillips AN, Lee CA, Elford J, et al. Serial CD4 lymphocyte counts and development of AIDS. Lancet 1991;337:389-92.

26 Shephard RJ. Exercise, immunity and susceptibility to infection. Phys Sportsmed 1999;27:47-71.

27 Shek PN, Sabiston BH, Buguet A, et al. Strenuous exercise and immunological changes: a multiple-time-point analysis of leukocyte subsets, CD4/CD8 ratio, immunoglobulin production and NK cell response. Int J Sports Med 1995: 16:466-74.

28 Bauer T, Weisser B. [Effect of aerobic endurance exercise on immune function in elderly athletes]. Schweiz Rundsch Med Prax 2002;91:153-8.

29 Rehman J, Mills PJ, Carter SM, et al. Dynamic exercise leads to an increase in circulating ICAM-1: further evidence for adrenergic modulation of cell adhesion. Brain Behav Immun 1997; 11:343-51.

30 Miles MP, Leach SK, Kraemer WJ, et al. Leukocyte adhesion molecule expression during intense resistance exercise. J Appl Physiol 1998;84:1604-9.

31 van Eeden SF, Granton J, Hards JM, et al. Expression of the cell adhesion molecules on leukocytes that demarginate during acute maximal exercise. J Appl Physiol 1999;86:970-6.

32 Kurokawa Y, Shinkai S, Torii J, et al. Exercise-induced changes in the expression of surface adhesion molecules on circulating granulocytes and lymphocytes subpopulations. Eur J Appl Physiol 1995;71:245-52.

33 Mills PJ, Goebel M, Rehman J, et al. Leukocyte adhesion molecule expression and $T$ cell naive/memory status following isoproterenol infusion. J Neuroimmunol 2000;102:137-44.

34 Goebel MU, Mills PJ. Acute psychological stress and exercise and changes in peripheral leukocyte adhesion molecule expression and density. Psychosom Med 2000;62:664-70

35 Bevilacqua MP. Endothelial-leukocyte adhesion molecules. Annu Rev Immunol 1993;11:767-804.

36 Picker LJ, Siegelman MH. Lymphoid tissues and organs. In: Pual WE, ed. Fundamental immunology. Lippincott-Raven, 1999:479-531.

37 Lichtman AH, Ding H, Henault L, et al. CD45RA-RO+ (memory) but not $\mathrm{CD} 45 \mathrm{RA}+\mathrm{RO}$ - (naive) T cells roll efficiently on $\mathrm{E}$ - and $\mathrm{P}$-selectin and vascular cell adhesion molecule-1 under flow. J Immunol 1997;158:3640-50.

38 Newman I, Wilkinson PC. Locomotor responses of human CD45 lymphocyte subsets: preferential locomotion of CD45RO+ lymphocytes in response to attractants and mitogens. Immunology 1993;78:92-8.

39 Bonneau RH, Zimmerman KM, Ikeda SC, et al. Differential effects of stressinduced adrenal function on components of the herpes simplex virus-specific memory cytotoxic T-lymphocyte response. J Neuroimmunol 1998;82:191-9.

40 Hamann D, Baars PA, Rep MH, et al. Phenotypic and functional separation of memory and effector human CD8+ T cells. J Exp Med 1997;186:1407-18.

41 Roebuck KA, Finnegan A. Regulation of intercellular adhesion molecule- 1 (CD54) gene expression. J Leukoc Biol 1999:66:876-88.

42 Cengizlier R, Demirpolat E, Tulek N, et al. Circulating ICAM-1 levels in bronchial asthma and the effect of inhaled corticosteroids. Ann Allergy Asthma Immunol 2000;84:539-41

43 Marguet C, Dean TP, Warner JO. Soluble intercellular adhesion molecule-1 (sICAM-1) and interferon-gamma in bronchoalveolar lavage fluid from children with airway diseases. Am J Respir Crit Care Med 2000; 162:1016-22.

44 Lantero S, Alessandri G, Spallarossa D, et al. LFA-1 expression by blood eosinophils is increased in atopic asthmatic children and is involved in eosinophil locomotion. Eur Respir J 1998;12:1094-8.

45 MacKelvie KJ, Khan KM, McKay HA. Is there a critical period for bone response to weight-bearing exercise in children and adolescents? a systematic review. Br J Sports Med 2002;36:250-7. 